\title{
UN NUEVO CAMINO EN SANTIAGO, EL PERIFÉRICO DE COMPOSTELA
}

\section{(A NEW ROAD IN SANTIAGO, THE COMPOSTELA RING ROAD)}

\author{
Angel González del Río \\ Ingeniero Director de las obras de la Demarcación de Carreteras del Estado en Galicia. MOPTMA
}

ESPAÑA

Fecha de recepción: 12-VI-95

\section{RESUMEN}

Se presentan los planteamientos de planificación, proyecto y obra del nuevo periférico de Santiago recientemente puesto en servicio.

Las peculiaridades históricas, artísticas, culturales y medioambientales de la ciudad, han exigido desarrollar un proyecto especialmente respetuoso con su entorno humano, urbano y natural.

\section{SUMMARY}

The article presents the approaches to planning, design and work execution of the new Santiago ring road, recently open for traffic.

The historical, artistic, cultural and environmental peculiarities of Santiago called for the development of a project that would respect with particular care the city's human, urban and natural surroundings.

\section{Aspectos más destacables del marco institucional}

El 18 de noviembre de 1991 se firma el Convenio entre el Ministerio de Obras Públicas, Transportes y Medio Ambiente y el Ayuntamiento de Santiago de Compostela. Se trata del punto de partida para un ambicioso plan sectorial y urbanístico que de una forma integrada sienta las bases para un profunda transformación de la ciudad de Santiago de Compostela.

Dentro del período 91-99 en el que se desarrolla la planificación existen dos años clave que enmarcan las actuaciones, los Años Jubilares 93 y 99.

Las especiales connotaciones históricas y culturales, el crecimiento que experimenta la ciudad al convertirse en capital de Galicia y el año Santo Jacobeo 1993 conforman referencias obligadas al concertar actuaciones.
Las bases fundamentales del Convenio son las siguientes:

a) Ejecución del nuevo periférico de la ciudad en 7 tramos que han de conectar las carreteras nacionales N-550 (La Coruña-Vigo y Tuy), N-634 (Santiago-San Sebastián) y N-525 (Zamora-Orense-Santiago), así como los tres enlaces de la Autopista A-9 con la ciudad.

b) Desarrollo de acciones de ampliación y remodelación del Aeropuerto de Labacolla.

c) Ejecución de la Autovía Santiago-Aeropuerto

d) Coordinación entre administraciones para la correcta acomodación de las nuevas infraestructuras al planeamiento urbanístico en vigor.

e) Desarrollo del Convenio RENFE-Ayuntamiento, bajo 
tutela del MOPTMA, desarrollándose diversas actuaciones de remodelación en las estaciones de Cornes y La Sionlla.

f) Actuaciones en materia de rehabilitación de la ciudad histórica y programas medioambientales.

g) Tratamientos de borde de las nuevas infraestructuras, al objeto de acomodarlas e integrarlas en el tejido urbano.

El 11 de octubre de 1993 se firma un protocolo entre la Secretaría General para las Infraestructuras y el Ayuntamiento de Santiago que desarrollaba este último punto concretando actuaciones urbanísticas de borde urbano que afectaban a distintos barrios de Santiago, que de este modo se integraban al nuevo eje de comunicación y desarrollo que constituye el Periférico de la ciudad.

\section{Antecedentes del periférico}

Los antecedentes del periférico de Santiago han sido dos básicamente.

1.- La Red Arterial del MOP de 1972

2.- El Plan General de Ordenación Urbana de 1989

La red arterial del MOP planteada en 1972, partía de viarios y planificaciones urbanísticas que difieren sustancialmente de las actuales, con algunos aspectos comunes, como sucedía con el trazado del tramo CornesChoupana (Ronda Sur) que enlaza N-525 y N-550. La encendida polémica que surgió entre el planeamiento sectorial viario y los planes de ordenación de la época, supuso la inviabilidad de la red arterial propuesta entonces.

El PGOU de 1989 supuso un nuevo marco urbanístico para Santiago, contemplándose como sistemas generales de comunicación los suelos destinados a albergar el nuevo periférico

\section{3. ¿Qué es el periférico?}

El nuevo periférico de Santiago, es una vía segura de alta capacidad y accesibilidad a la trama urbana, que permite descongestionar los tráficos que afectan al centro histórico de la ciudad y conexionar entre sí las carreteras nacionales $\mathrm{N}-550, \mathrm{~N}-634, \mathrm{~N}-525$ y mejorar los accesos de la autopista A-9 en sus distintos enlaces urbanos.

El nuevo vial viene a resolver además los graves problemas de accesibilidad que sufrían el polígono industrial del Tambre, en fuerte proceso expansivo, el nuevo Palacio de Congresos con capacidad para 1.500 congresistas instalado en S. Lázaro, el estadio multiusos de S. Lázaro con capacidad para 12.000 espectadores, el centro de acogida de peregrinos ubicado en el Monte del Gozo, el polígono de Fontiñas que alberga un gran centro comercial y 4.000

(c) Consejo Superior de Investigaciones Científicas nuevas viviendas, el pabellón deportivo del Sar y los barrios tradicionales de Porto, Poza Real, Rocha Vella, Conxo, Castiñeiriño, Lamas de Abad, Viso, San Lázaro y Amio.

Santiago se articula ya, en torno a su periférico. La nueva vía de $10,5 \mathrm{~km}$ con 15 enlaces y $700 \mathrm{~m}$ de distancia media entre enlaces, que permite a Santiago, por un lado, superar sus límites tradicionales, abriendo nuevos espacios y perspectivas y, por otro, recoge e integra en la ciudad sus barrios periféricos y sus nuevos equipamientos culturales y deportivos.

En la figura 1 se detalla el modo en el que se implanta el trazado del periférico en el territorio. Su alineación, formando un gran arco al este de la ciudad, constituye un tercer eje infraestructural, sumándose así a la autopista del Atlántico y al ferrocarril La Coruña-Santiago-Vigo.

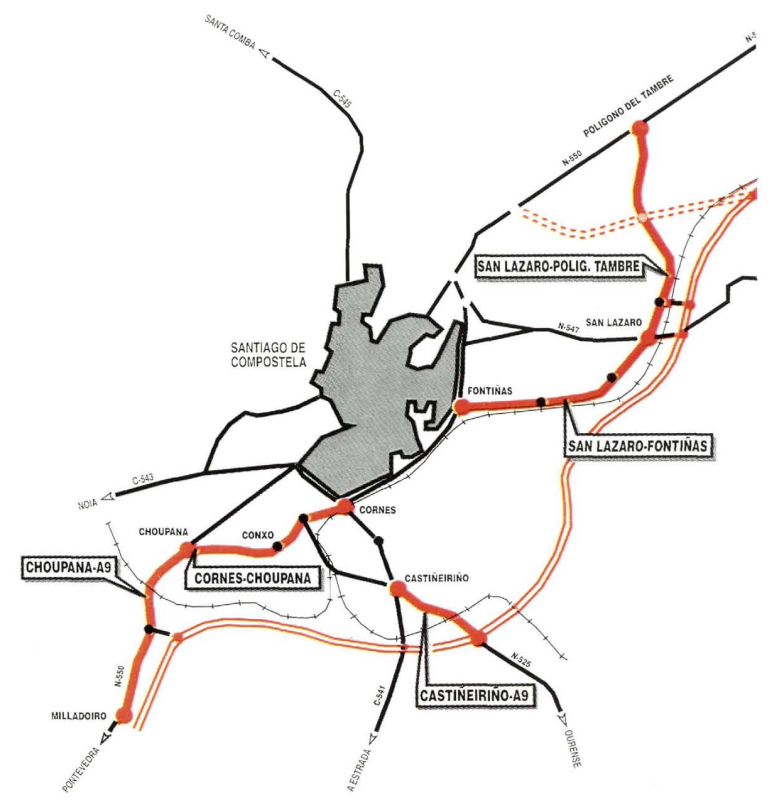

Fig. 1.- El Periférico de Santiago.

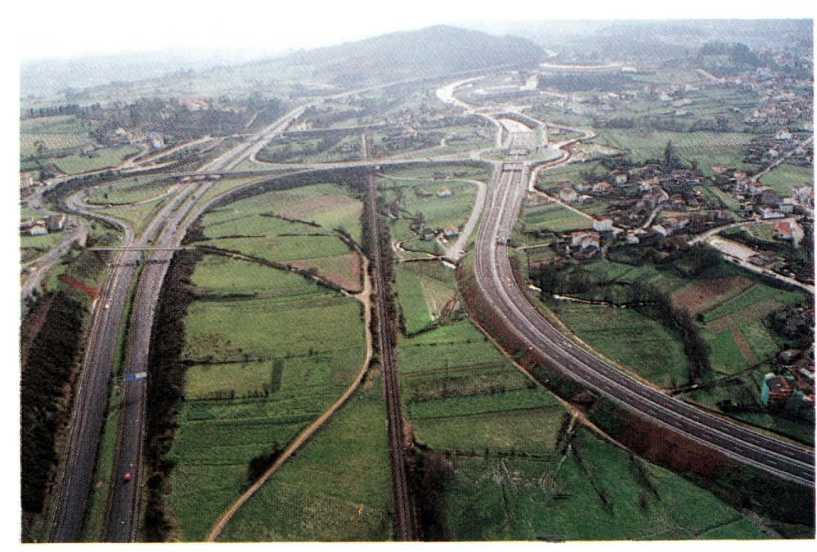

Fig. 2.- Una vista panorámica de los 3 ejes de infraestructuras: A-9, ferrocarril y periférico. 
En la figura $n^{\circ} 2$ se aprecian estos tres grandes ejes de infraestructuras, que son atravesados por el río Sar en distintos puntos.

El periférico, es por otra parte susceptible de ser cerrado completamente por el Oeste como anillo de circunvalación en un futuro próximo, recogiendo las carreteras autonómicas de Noya (salida hacia las playas) y San Comba, si bien, existen suelos de especial protección en el entorno del Monte Pedroso que condicionan las posibles soluciones de trazado.

Los seis objetivos del periférico son:

1) Creación de una infraestructura segura y cómoda que mejore la movilidad de Santiago y su entorno para tráficos internos y externos.

2) Permitir un desarrollo urbano planificado y ordenado.

3) Mejorar la calidad-ambiental del casco Histórico, drenando tráficos hacia la nueva red viaria.

4) Proporcionar conexiones con la malla urbana en los polígonos industriales, barrios tradicionales, nuevas zonas residenciales y equipamientos culturales, deportivos, comerciales y sanitarios.

5) Establecer la conexión de la red planificada con el sistema nacional de carreteras del Estado y Autopistas. De este modo quedaban interconectadas la N-550 (La Coruña, Pontevedra, Vigo y Tuy), N-634 (Oviedo), N-547 (Lugo) y N-525 (Orense), así como los tres enlaces de la A-9 en Santiago.

6) Lograr que la obra respetase el equilibrio ambiental y conseguir unos acabados y calidades acordes con la ciudad en la que se integra.

\section{El periférico tramo a tramo}

A modo de rápido viaje de Norte a Sur a través de la nuevainfraestructura, pasaremos sobre los cincotramos puestos en servicio el pasado 31 de enero de 1995 y los dos que actualmente se hallan en ejecución comentando sus aspectos más singulares.

\section{1.- Polígono del Tambre-San Lázaro}

El tramo une el polígono industrial del Tambre y la N-550 con el enlace Santiago Norte de la Autopista A-9 y la N-634 (Oviedo, Lugo).

Los aspectos particulares reseñables del tramo son:

-Se produjo una afección parcial de los taludes del antiguo vertedero municipal de basuras, motivando especiales

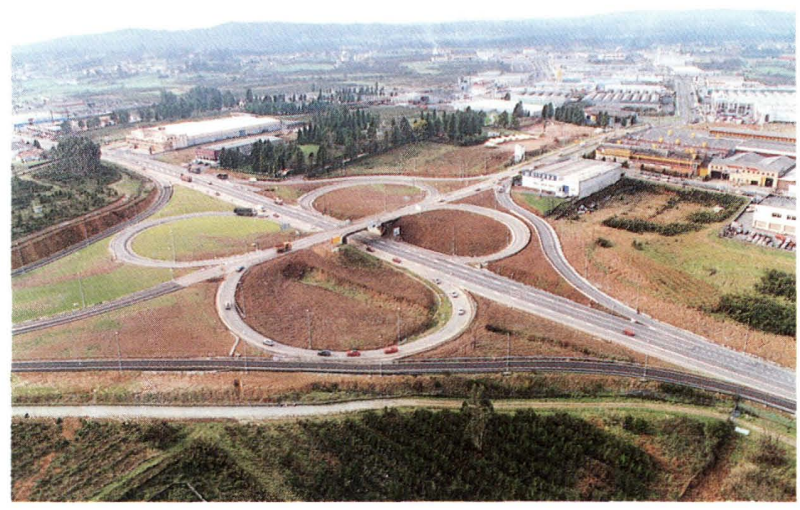

Fig. 3.- Enlace del Poligono Industrial del tambre.

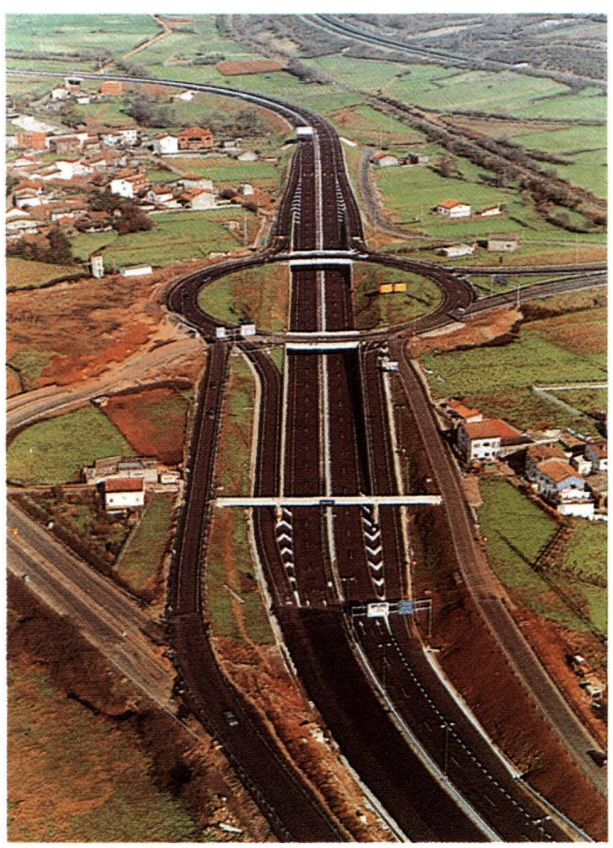

Fig. 4.- Enlace con la A-9 (Norte).

medidas correctoras del impacto visual mediante plantaciones.

-Enlace periférico- Polígono del Tambre.Resuelto mediante un trébol completo.

-Especial tratamiento de los fondos de excavación en la zona denominada "Brañas del Sar" (zona inundable en la que nace el río Sar) con sustitución de los dos primeros metros de fango y aportación de piedra sana a efectos de cimentar la nueva infraestructura.

-Enlace periférico - A-9 (Norte). Resuelto mediante un diamante con glorieta superior. Esta tipología de enlace ha sido la adoptada con carácter general en todo el periférico, por las ventajas que presentaba en cuanto a seguridad, sencillez, capacidad y pequeña demanda de suelo frente a otras tipologías. De este modo la movilidad sobre el 
periférico no queda interrumpida en los enlaces y los tráficos genuinamente locales se resuelven en laglorieta en un nivel diferente, quedando así jerarquizado el viario. Las estructuras son dos losas postesadas de $24,2 \mathrm{~m}$ de longitud y $11,50 \mathrm{~m}$ de ancho, cuya planta es una corona circular de $45 \mathrm{~m}$ de radio interior.

-El barrio de S. Lázaro es atravesado con una rasante deprimida entre muros que evita impactos visuales y de ruidos. El enlace de S. Lázaro, análogo al anterior enlaza con la N-634 (Oviedo), N-547 (Lugo) y el aeropuerto internacional de Labacolla.

-Se hatenido especial atención en el cuidadode la reposición del Camino de Santiago (Camino Francés) en su paso por S. Lázaro, disponiendo aceras y acabados de muros con pizarra de Santiago, que ciignifican tan insigne itinerario.

-En los distintos muros ejecutados buscamos lograr una gran calidad constructiva y estética, compatible con la rapidez de ejecución. Diseñamos así, sobre la base de los muros prefabricados texturizados, un sencillo elemento que es la tradicional concha del peregrino, buscando que el usuario del periférico tuviera la sensación inequívoca de hallarse en Compostela.
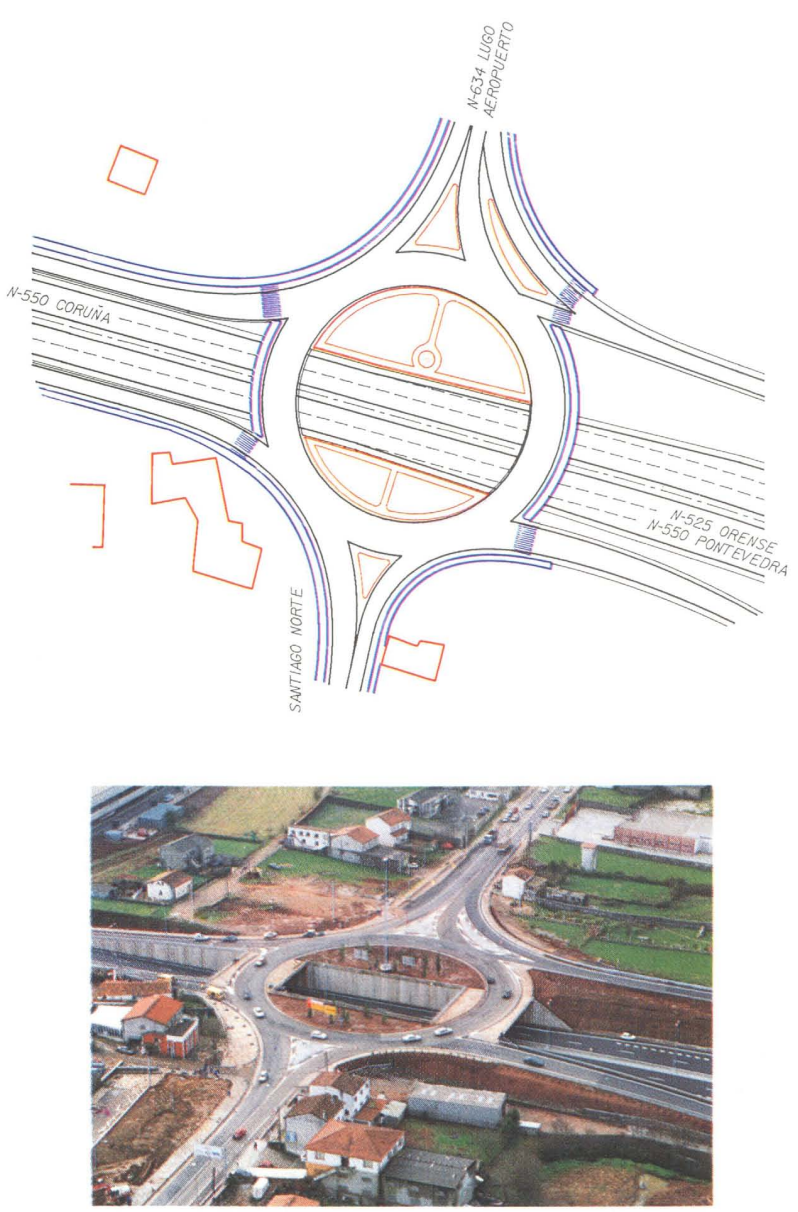

Fig. 5.- Enlace de San Lázaro.

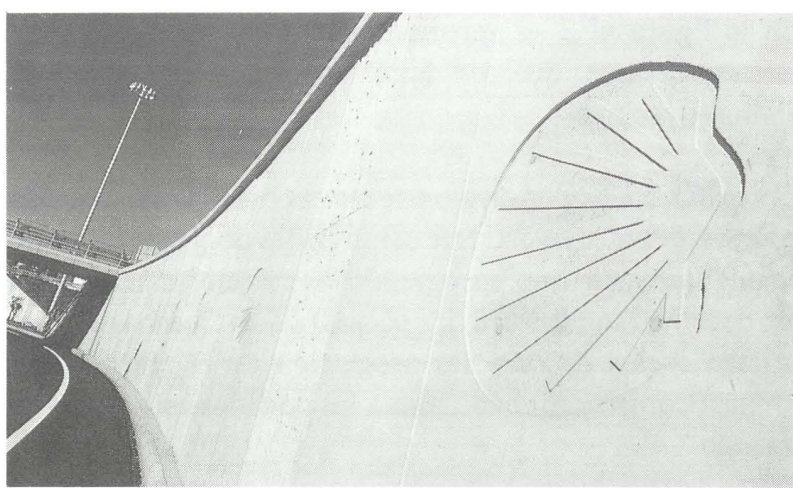

Fig. 6.- Detalle de los muros ilustrados con motivos Jacobeos.

Además, dicho símbolo, que sirve para señalizar los distintos Caminos hacia Santiago, cumple esta misma misión específica sobre los alzados de los muros del periférico, indicando al usuario como acceder a la universal plaza del Obradoiro

\section{2. - San Lázaro-Fontiñas Sur}

E1 tramo une N-634 y N-550 (Avda. de Lugo), proporcionando accesibilidad a los nuevos equipamientos culturales y deportivos de la ciudad, así como al polígono residencial de Fontiñas.

Se podrían destacar como aspectos más interesantes del tramo, los siguientes:

-En cuanto al medio físico y su geología, la traza se asienta en lasinmediaciones del cauce del río Sar, con predominio en el sustrato rocoso de esquistos, anfibolitas y suelos limoarcillosos, procedentes de la alteración de dicho substrato. Una constante del tramo fue la gran heterogeneidad del material, pasándose de zonas rocosas a zonas arcillosas sin material de tránsito. Dicha heterogeneidad se puso de manifiesto al acometer la cimentación de la estructura del enlace del estadio de fútbol de la S.D. Compostela, donde el estribo Sur se ejecutaba con cimentación directa y el estribo Norte con cimentación indirecta, mediante pilotes in situ de $1,50 \mathrm{~m}$ y $20 \mathrm{~m}$ de profundidad, quedando la cimentación de las pilas intermedias en cotas aproximadamente interpoladas entre ambos valores.

-Dicho enlace, proporciona acceso al estadio de la S.D. Compostela (S. Lázaro), al nuevo Palacio de Congresos con capacidad para más de 1.500 personas y al vial que comunica con el recinto del Monte del Gozo, donde se ubica el centro de acogida de peregrinos.

En este caso, el tronco del periférico pasa sobre la glorieta inferior, uniéndose a ella mediante un diāmante completo, construyéndose una losa postesada de tres vanos y $80 \mathrm{~m}$ de luz total, ejecutándose los dos tableros separados para 


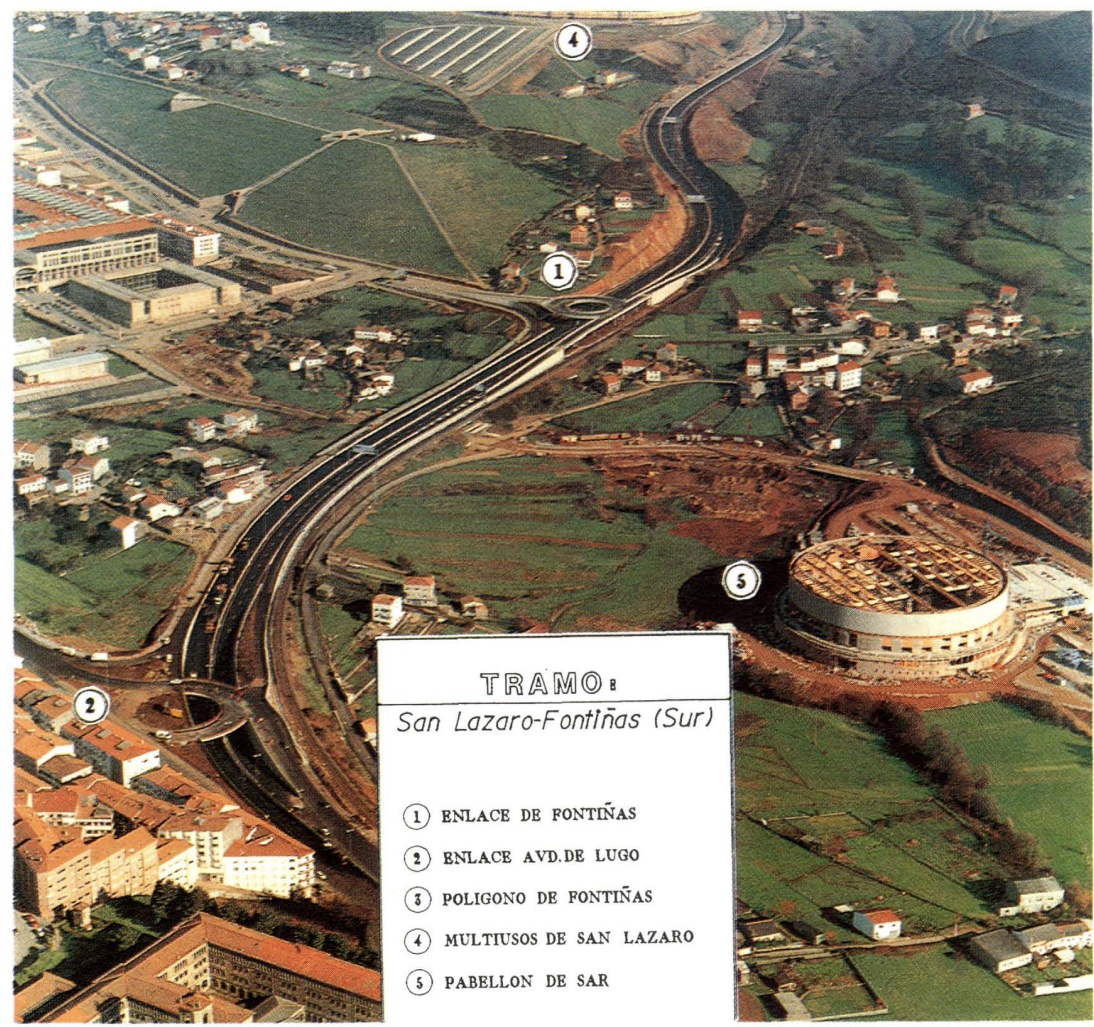

Fig. 7.- Tramo San Lázaro-Fontiñas Sur.
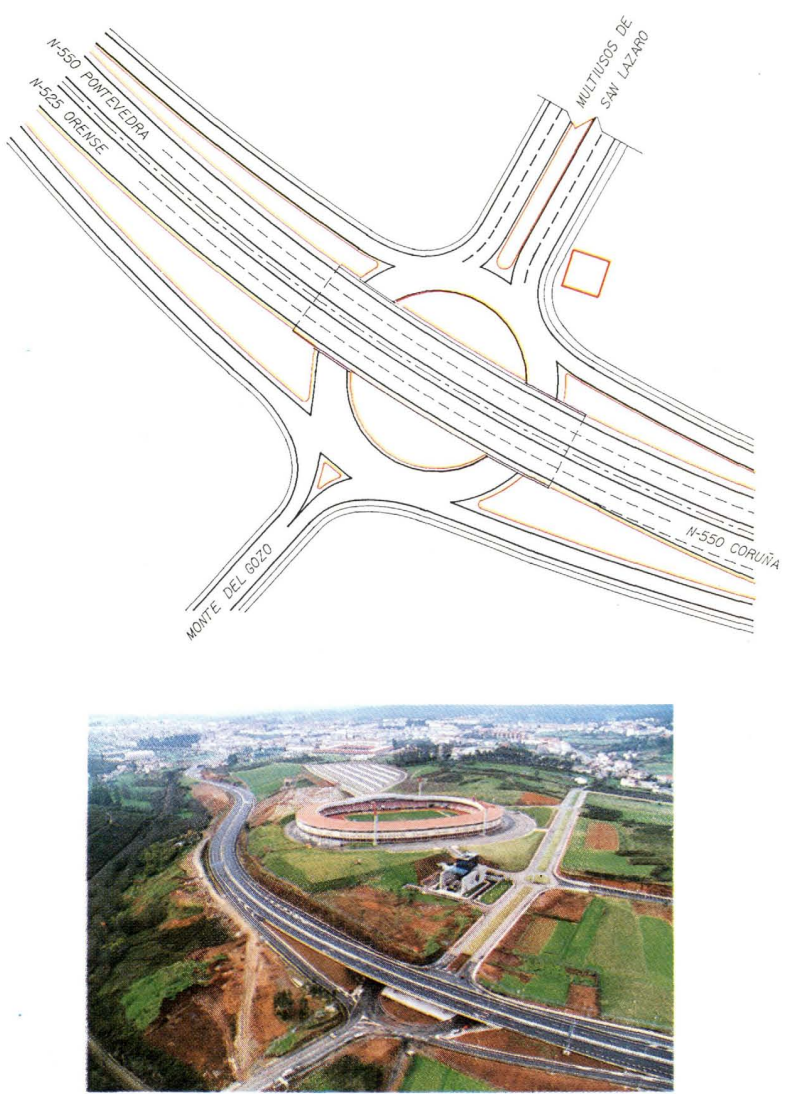

Fig. 8.- Enlace multiusos de San Lázaro. realizar, posteriormente, la unión de ambos para que tengan un comportamiento resistente solidario. En el acceso al Monte del Gozo se ejecutó una estructura mixta formada por un cajón metálico de acero cortén y losa superior en un solo vano de $40 \mathrm{~m}$ que salva el río Sar y el Ferrocarril.

-Las arcillas de la traza en este tramo tenían una elevada plasticidad, lo cual, unidoal rigor climatológico de Santiago, ha impedido su puesta en obra.

-El enlace de Fontiñas, sobre el que D. Fernando da Cunha Rivas, Ingeniero Autor del Proyecto, ha escrito un artículo específico dentro de este número especial dedicado a Santiago, es una bella, diáfana y funcional realización, que resuelve con elegancia, en un exiguo espacio entre el ferrocarril y el propio polígono, el acceso a Fontiñas, donde se ubican en simbiosis urbana usos residenciales $(4.000$ viviendas), administrativos (nuevos juzgados y dependencias de la Xunta), deportivos (nuevo pabellón deportivo y piscinas del Sar) y comerciales (Área Central).

Por su ubicación, permeabilidad visual y solución constructiva, el enlace de Fontiñas se convierte en uno de los elementos singulares del periférico. Su permeabilidad transversal fue condicionante básico de diseño al efecto de no introducir labarrera visual que hubiera supuesto ejecutar muros y terraplenes entre las zonas de $\overline{\text { Sar }}$ (donde se halla la joya románica de la Colegiata de Sar) y Fontiñas. La 
estructura de la glorieta superior es una lcsa pretensada con planta de corona circular de $18,25 \mathrm{~m}$ de radio en el eje y $11,40 \mathrm{~m}$ de anchura transversal. El ramal permeabilizado, es una losa pretensada de $117 \mathrm{~m}$ de longitud total y 7,10 m de anchura. Los pilares en $\mathrm{V}$, dispuestos perimetralmente, contribuyen decisivamente al airoso resultado de la estructura.

-La construcción de las nuevas piscinas y pabellón del Sar a las que habíamos de proporcionar acceso, unido a la barrera urbanística que suponía el terraplén existente del ferrocarril La Coruña-Santiago-Vigo en la zona de Sar, hizo que nos decantásemos por la solución de construir un paso inferior de hormigón armado por empuje oleodinámico de grandes dimensiones ( $15 \mathrm{~m}$ de gálibo horizontal, $5 \mathrm{~m}$ de gálibo vertical y $24 \mathrm{~m}$ de longitud, para salvar el terraplén RENFE). El empuje lo proporcionaron 24 gatos de $200 \mathrm{t}$, con un esfuerzo máximo de empuje de $3.230 \mathrm{t}$ y el peso propio de la estructura $(2.430 \mathrm{t})$. Fue necesario sobredimensionar la potencia máxima de empuje para repartir mejor las cargas y aliviar los esfuerzos en el muro de reacción, a efectos de no correr riesgos de rotura del sistema de tuberías existentes de pluviales y saneamiento de Fontiñas, que estaban bajo el cajón, quedando así, desafectadas. Se procedió al empuje del cajón, vaciando simultáneamente el terraplén de la vía, no siendo preciso alterar los tráficos ferroviarios en ningún momento.
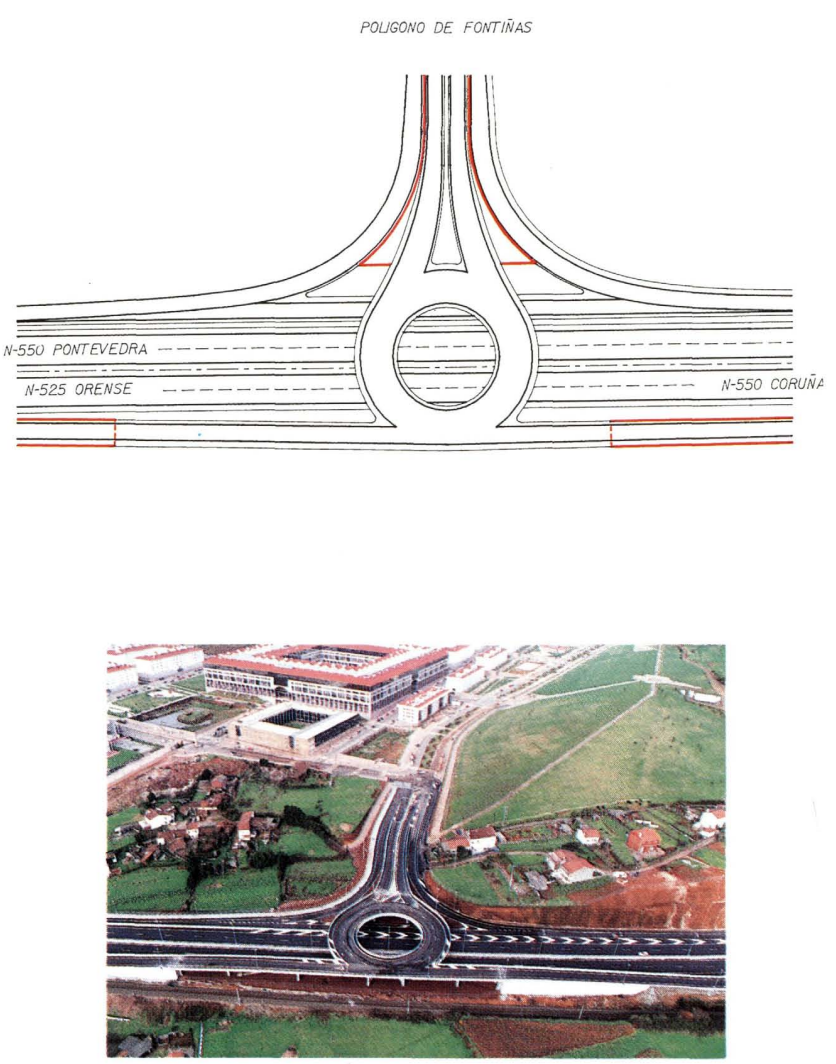

Fig. 9.- Enlace de Fontiñas.

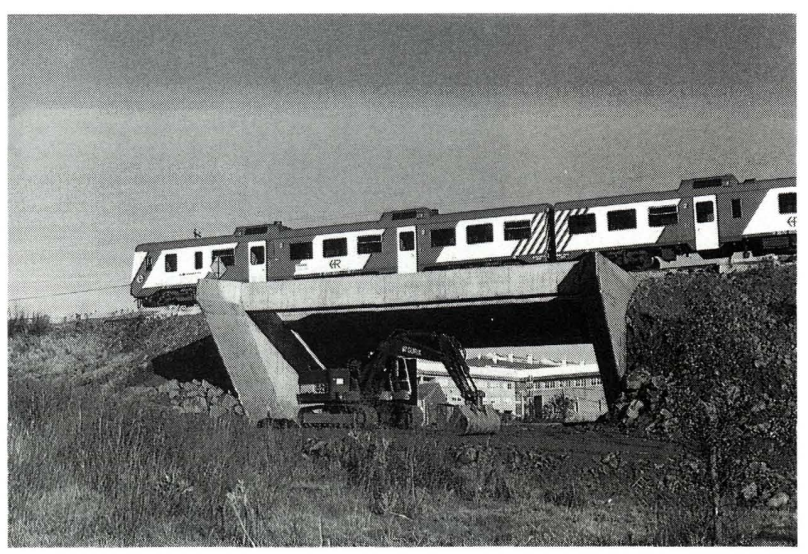

Fig. 10.- Cajón empujado bajo FFCC. La Coruña-Vigo.
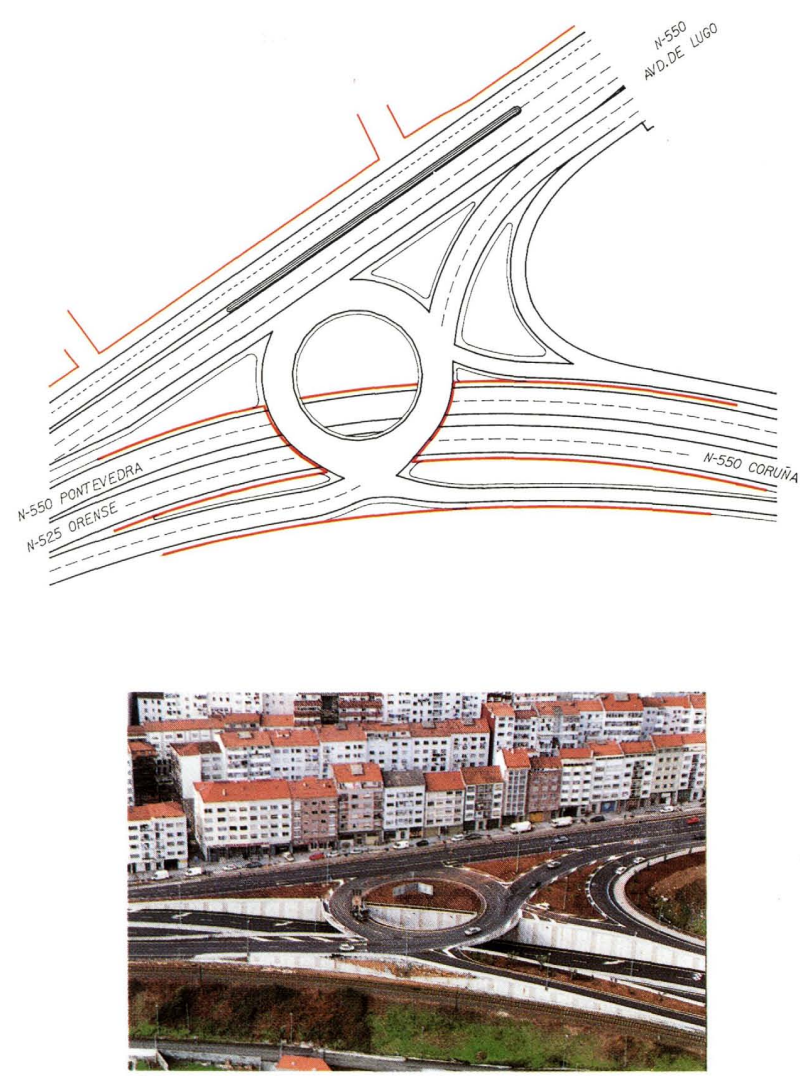

Fig. 11.- Enlace avda. de Lugo.

-Finalizaba este tramo con el enlace con la N-550 en su tramo urbano conocido como avda. de Lugo. El periférico enlaza así con la antigua ronda, cuya sección transversal también se remodela y ensancha.

El enlace de la avda. de Lugo, se realiza deprimiendo entre muros el tronco del periférico, quedando la glorieta en el plano superior, coincidente con la rasante existente de la antigua circunvalación. La estructura es ūna losa postesada, con planta de semi-corona circular apoyada en tres estribos. 


\section{3.-Ampliación de la Avda. de Lugo (Fontiñas Sur-Cornes)}

Se trata del único tramo del periférico, en el que se aprovechael tramo existente, ampliándosey reordenándose la sección transversal, dotada de tres carriles por sentido, con aparcamientos y amplias aceras.

Actualmente se halla en fase de ejecución, estando prevista su puesta en servicio en Otoño de 1996. Incluye como obras singulares:

-Resolver la afección del talud de Bellvis, sobre el que se halla el Seminario Menor de Santiago ,mediante la técnica del "talud claveteado", con bulones de 4-5 m, gunitado y revestimiento.

-Ejecutar en voladizo parte de la calzada y acera en el entorno de la estación de ferrocarril de Cornes.

-Construcción de un nuevo enlace en Sar que permitirá efectuar un by-pass entre tráficos $\mathrm{N}-525 / \mathrm{N}-550$ desafectando la glorieta de Cornes, que es el punto con mayor carga de tráfico de Santiago (IMD $=45.000$ ), ejecutando un cajón empujado bajo el haz de vías.

\section{4.- Cornes - Choupana}

Este tramo del periférico es prácticamente idéntico al que ya recogía el estudio de la Red Arterial de 1972 del MOP. Enlaza la N-525 (Zamora-Orense-Vigo) y la N-550 (Pontevedra), atravesando el tradicional barrio de Conxo. Sus nudos y aspectos más destacables son:

-Nueva glorieta de Cornes que recoge los tráficos de la antigua N-525 y la c/ Romero Donallo, actual salida hacia la Universidad, Noya y playas. Hay que significar que la Xunta de Galicia está desarrollando el proyecto La RochaVidán, nuevo tramo del periférico que permitirá enlazar la N-550 (Pontevedra) con la C-543 (Noya).

-Nuevo enlace con el tramo del periférico CornesCastiñeiriño que constituirá la nueva salida hacia Orense (N-525).

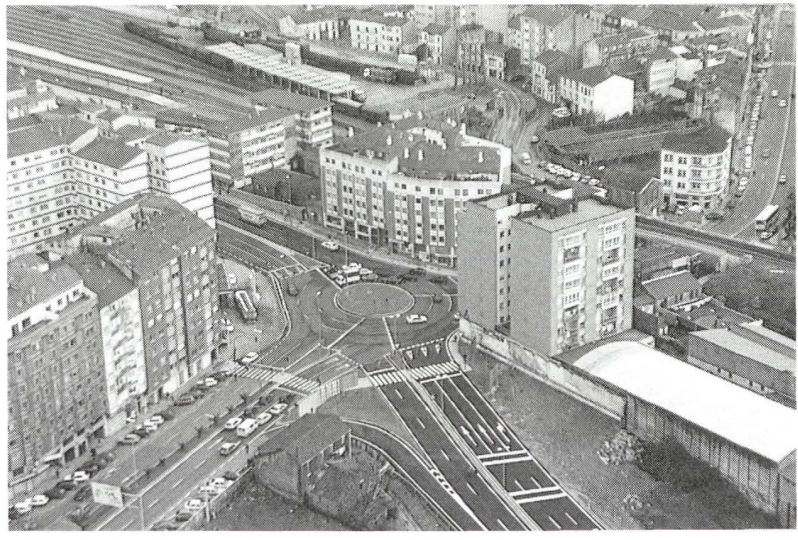

Fig. 12.- Glorieta de Cornes.

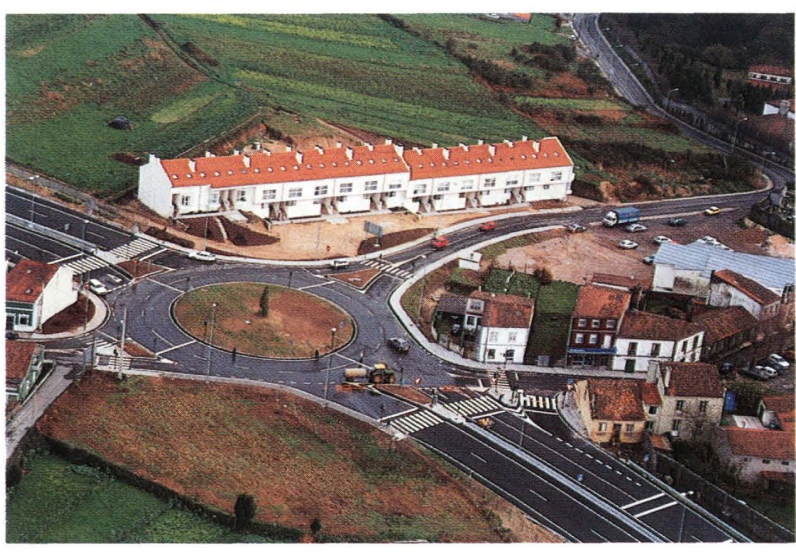

Fig. 13.- Glorieta de Conxo.

-Glorieta en Conxo para conectar dicho barrio con el periférico.

-Se construyen dos importantes permeabilizaciones en el Pajonal y Torrente resueltas con losas postesadas de $125 \mathrm{~m}$ y $140 \mathrm{~m}$, donde el PGOU desarrollará futuros viales y zonas verdes.

Finaliza el tramo en el nudo de La Choupana, resuelto mediante un diamante con glorieta superior. Su amplio
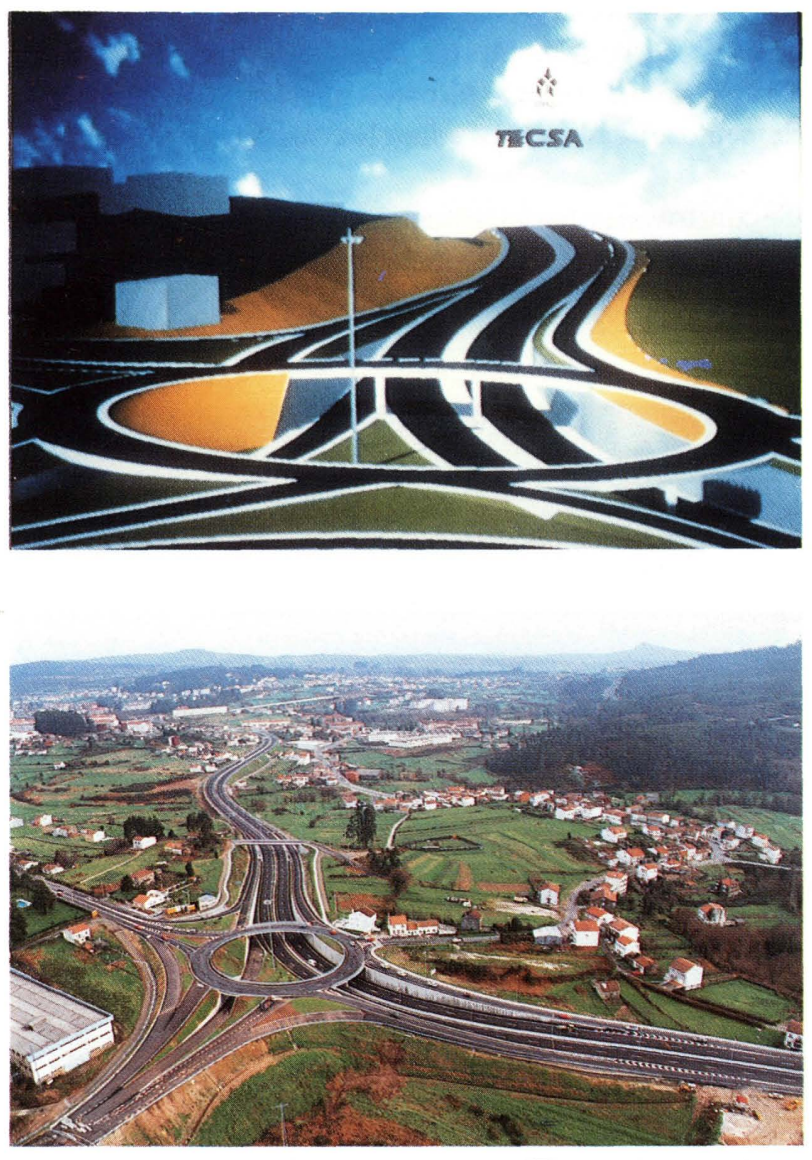

Fig. 14.- Imagen virtual del Enlace de la Choupana (arriba). Enlace de la Choupana (abajo). 
campo visual hizo que estudiásemos muy especialmente el diseño de este enlace, realizando distintas imágenes virtuales que nos permitieron optimizar la solución.

En este nudo queda prevista con un paso inferior la futura conexión con la carretera autonómica C-543 a Noya.

-Fue tratada específicamente la reposición del itinerario peatonal relativo al Camino Portugués hacia Santiago.

\section{5. - Choupana - A-9}

Este tramo es una adaptación de la sección tipo de la antigua carretera de 2 carriles $\mathrm{N}-550$, a la nueva del periférico.

Las singularidades más destacadas del tramo son las siguientes:

-Se ha ampliado el antiguo Puente de la Rocha en la N-550 (Pontevedra), que salva una pronunciada vaguada de unos $260 \mathrm{~m}$ sobre el río Sar. Es una obra singular dentro del periférico, que ha precisado idear un original sistema constructivo para poder ampliar la sección transversal, desde $10 \mathrm{~m}$ a $22 \mathrm{~m}$, sin afectar el tráfico del acceso desde Pontevedra y Vigo a Santiago (IMD=22.000). En un artículo especifico dentro de esta misma revista, D. José Antonio Barbosa Ayúcar, Ingeniero proyectista y Jefe de Obra de Dragados, explica detalladamente la génesis y desarrollo de la técnica aplicada en esta obra, realizada con elementos prefabricados (dinteles, soportes y vigas).

-Se construyeron también nuevas conexiones con los barrios de Rocha Vella y Porto, mejorando el control de dichos accesos.

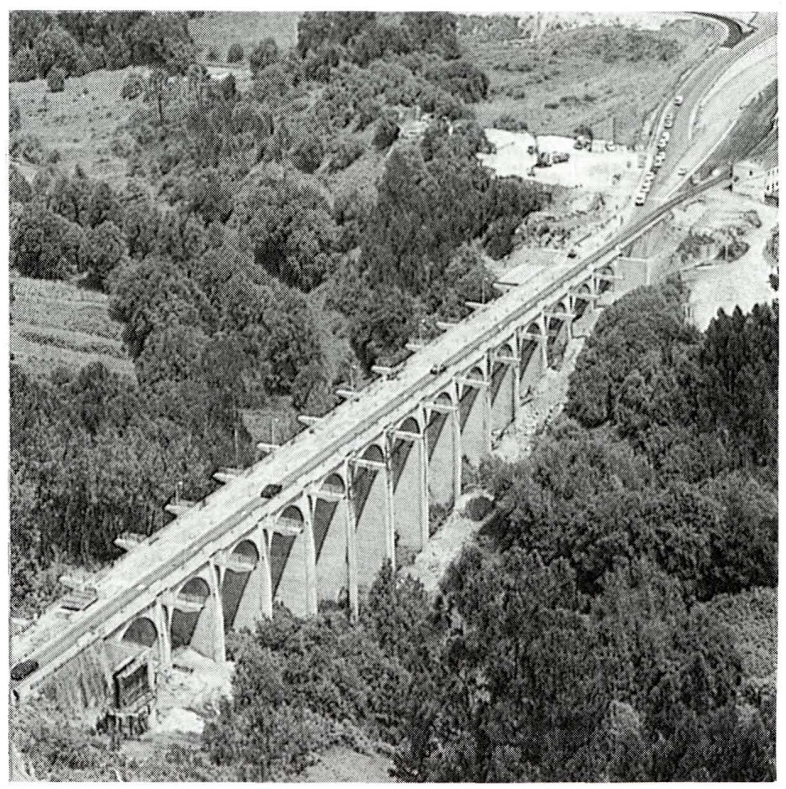

Fig. 15.- El Puente de la Rocha, tras la colocación de dinteles.

\section{6.- Castiñeiriño-Cornes}

-Supone el desarrollo del nuevo acceso de la N-525 (OrenseSantiago) a Compostela, totalmente en variante.

-En el nudo de Cornes se dispone un paso inferior para los vehículos que saldrán hacia Orense.

-Posteriormente, para salvar las vías del tren y la vaguada existente entre Cornes y el Monte do Xeixo, proyectamos un gran viaducto de $450 \mathrm{~m}$, que salvaba la vaguada y las vías del ferrocarril Santiago-Vigo y Santiago-Orense, y que se bifurcan en este punto, con gran esviaje respecto al trazado del nuevo vial. La estructura se rechaza en 15 vanos isostáticos de $30 \mathrm{~m}$ de longitud, con vigas artesa y cimentaciones directas, generalmente.

-Finalmente, el tramo llega al Castiñeiriño, barrio tradicional de Santiago que se salva con un paso inferior, para evitar impactos visuales y de ruidos en el barrio, resolviéndose en la glorieta superior los tráficos urbanos.

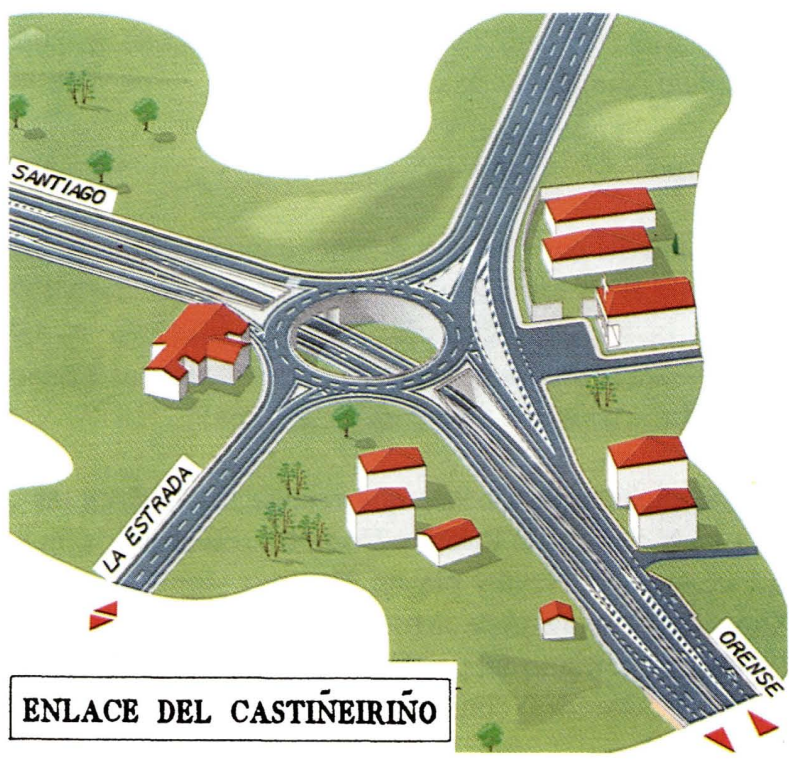

Fig. 16.- Virtualización del Enlace de Castiñeiriño (N-525).

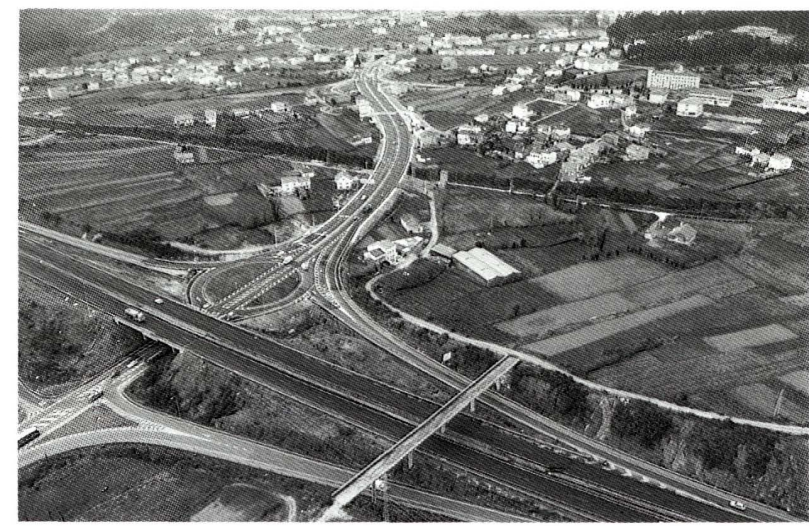

Fig. 17.- Tramo Castiñeiriño - $A-9$. 


\section{7.- Castiñeiriño-A-9}

Tramo que concluye el nuevo vial de acceso a Santiago de la N-525 (Orense - Santiago). Este tramo, continuación de la Variante Cornes-Castiñeiriño, supuso la readaptación de la antigua $\mathrm{N}-525$ a la nueva sección del periférico, resolviendo el control de accesos.

Las peculiaridades del tramo fueron:

-Generar un enlace en trompeta con el núcleo de Lamas de Abad y centros escolares de la zona.

-Disponer una nueva conexión con la A-9 (enlace N-525).

-Mejorar el control de accesos, generando vías de servicio.

-Ampliación del puente sobre el ff.cc. Santiago-Orense, adaptándolo a los gálibos prescritos por RENFE.

\section{Aspectos generales}

-La cifra de inversión final del periférico se sitúa en 10.000 millones, de los cuales 7.000 millones corresponden a la ejecución de la infraestructura ( 700 millones $/ \mathrm{km}$ ), 2.000 millones para expropiación (200 millones $/ \mathrm{km}$ ), 1.000 millones para los servicios afectados ( 100 millones $/ \mathrm{km}$ ).

-La sección tipo del periférico es uniforme, incluyendo firme drenante, barrera rápida y luminarias con báculos dobles de 9 y 12 m, con lámparas de VASP de $250 \mathrm{~W}$. En glorietas hemos preferido la solución de iluminar con torres de iluminación únicas de gran altura, centradas en la glorieta frente a la iluminación perimetral, para facilitar la percepción nocturna de los nudos.

-El capítulo de expropiaciones ha sido especialmente dificultoso, afectando a 90 edificaciones ( 70 viviendas y 20 naves y talleres) y a 1.500 fincas, estando precedido de

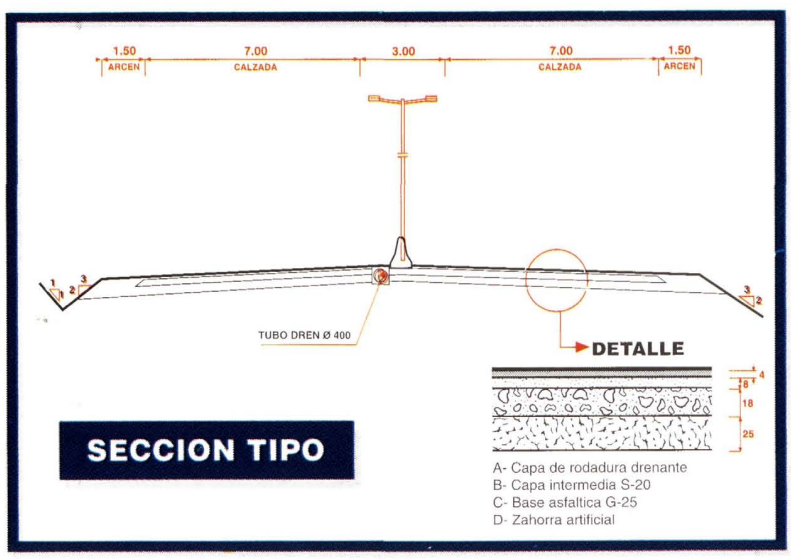

Fig. 18.- Sección tipo del Periférico. intensos trabajos y de reuniones con los afectados, para intentar resolver los problemas de sustitución de viviendas, reclamaciones legales y económicas, coordinando los plazos de ocupación de fincas y edificaciones, además de los programas de trabajo de las distintas obras.

A modo de ejemplo, destacaría la solución adoptada de forma conjunta para el modo de realojo que fue adoptado en el tramo Cornes-Choupana, donde los afectados por la expropiación de sus casas actuaron con promotores de las nuevas viviendas de sustitución, y que fueron construidas en una pieza de suelo urbanizable programado del barrio de Conxo. Los expropiados consiguieron el suelo a través de la firma de un convenio urbanístico que contemplaba la permuta de superficies, en función de las calificaciones urbanísticas del PGOU.

-Los servicios afectados por el periférico han sido repuestos de acuerdo con las secciones y demandas estimadas en el año horizonte del PGOU. Se han enterrado las líneas para evitar impactos visuales y se han creado galerías de servicios en los tramos en que se reordenaban y ampliaban las secciones existentes.

-De los 7 tramos, cuatro de ellos son variantes, con control total de accesos, y 3 tramos, readaptaciones de la sección transversal, en las que se han reordenado y restringido los accesos.

-Las características geométricas son homogéneas en planta y alzado con $\mathrm{R}_{\text {minimo }}=350 \mathrm{~m}$ y pendiente máxima del $5 \%$, salvo la rampa final de subida del Polígono del Tambre, que tiene un $6 \%$.

-Se ha cuidado especialmente la corrección de impa tos ambientales con plantaciones, hidrosiembras y pantallas arbóreas, especialmente útiles en un clima como el de Santiago, y tratamientos específicos de jardinería en cada enlace o glorieta, siempre con instalaciones de riegos por aspersión.

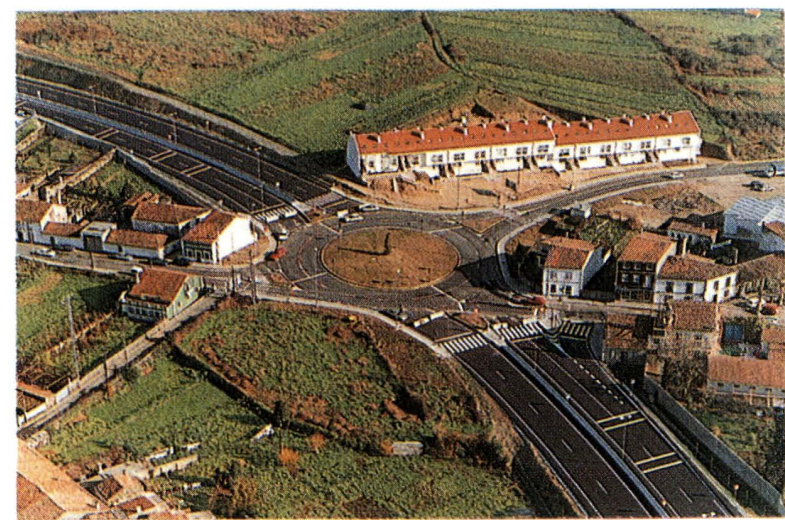

Fig. 19.- Viviendas de Conxo. 
-Todos los trazados en planta y alzado fueron almacenados en el ordenador de la Demarcación de Carreteras de Galicia del MOPTMA, permitiéndonos realizar ajustes, definir con precisión y agilidad detalles, y lograr una adecuada coordinación entre tramos.

\section{Conclusiones}

El recorrido a través del nuevo periférico de Santiago de Compostela nos ha mostrado una solución de red arterial urbana singular, que ha tratado de plantearse en consonancia con la propia singularidad de la ciudad.

Los nuevos viales constituyen un nuevo caminoen Santiago, que resolviendo los problemas específicos de accesibilidad de los barrios periféricos de la ciudad y los nuevos equipamientos urbanos, vienen también a aliviar las fuertes tensiones creadas por el tráfico dentro del casco histórico.

Me gustaría significar el alto grado de colaboración entre instituciones que se ha alcanzado en Santiago, que ha hecho posible, en muy corto espacio de tiempo, desarrollar todos los estudios previos, proyectos de trazado, construcción y ejecución de las obras

Quisiera agradecer al gran equipo humano que ha trabajadoen el periférico, en el que se han integradola Demarcación de Carreteras de Galicia del MOPTMA, el Ayuntamiento de Santiago de Compostela y las empresas constructoras y consultoras adjudicatarias de los distintos tramos, por el generoso esfuerzo y la gran ilusión depositada al servicio de la obra.

\section{Publicación del Instituto Eduardo Torroja - CSIC}

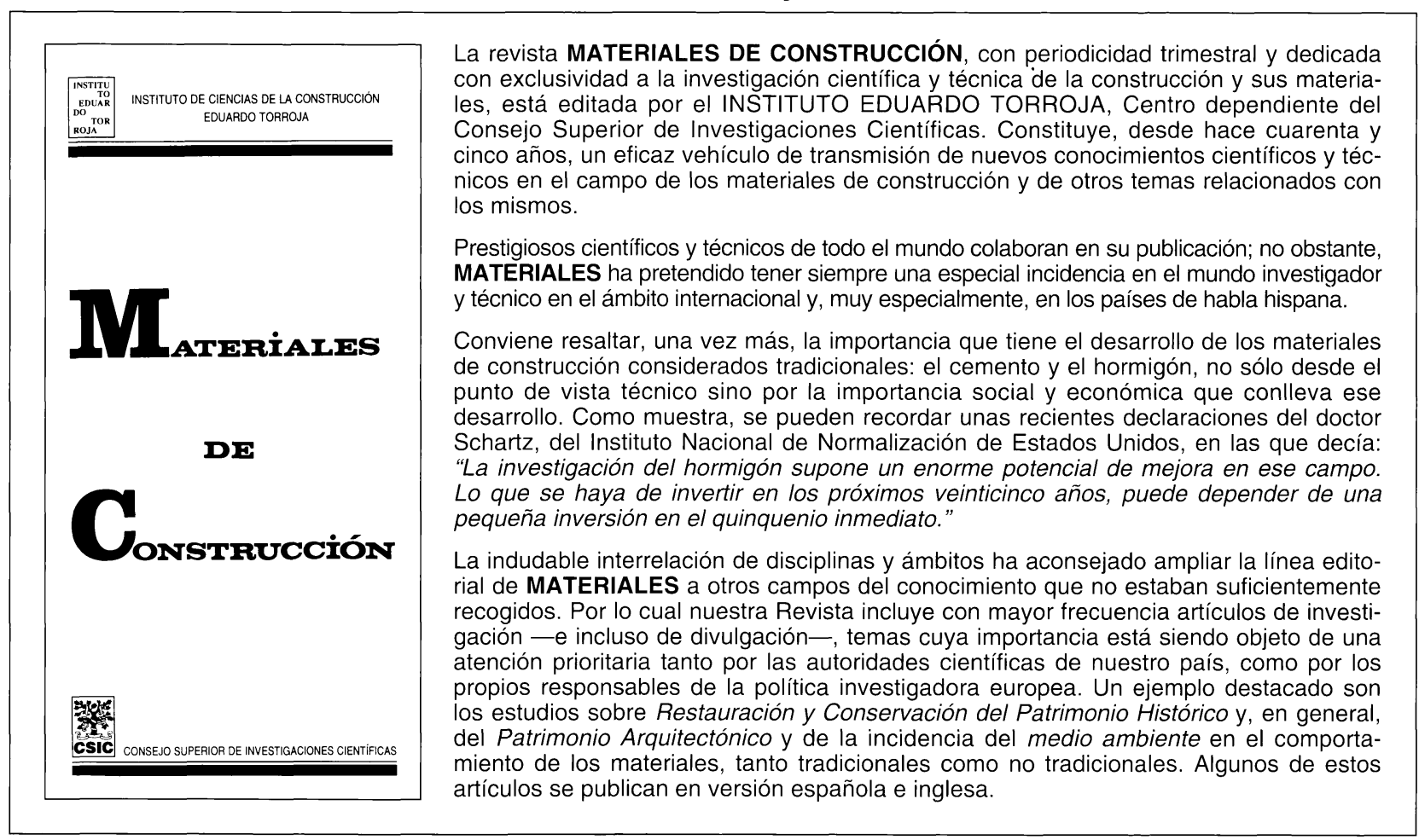

